\title{
When is the ideal time to remove cerclage in cases requiring cesarean hysterectomy for placenta accreta spectrum?
}

\author{
Futa Ito, Shinya Matsuzaki*, Masayuki Endo, Tadashi Kimura
}

Department of Obstetrics and Gynecology, Osaka University Graduate School of Medicine, Osaka, Japan

Received: 18 February 2019

Accepted: 25 February 2019

\author{
*Correspondence: \\ Dr. Shinya Matsuzaki, \\ E-mail: zacky@gyne.med.osaka-u.ac.jp
}

Copyright: () the author(s), publisher and licensee Medip Academy. This is an open-access article distributed under the terms of the Creative Commons Attribution Non-Commercial License, which permits unrestricted non-commercial use, distribution, and reproduction in any medium, provided the original work is properly cited.

\begin{abstract}
Placenta accreta spectrum (PAS) presents one of the highest risks to pregnancy and often requires a cesarean hysterectomy for management, but the challenges associated with this surgery often cause severe obstetric haemorrhaging and high rates of maternal morbidity. Shirodkar cerclage is usually performed in cases with cervical insufficiency, a short cervix with previous preterm birth, etc., to decrease the preterm birth rate. It is recommended that Shirodkar cerclage is removed when the patient approaches term, but the ideal timing of removal for patient for whom cesarean hysterectomy is planned is not clear. Here, authors present a case of PAS in whom Shirodkar cerclage that was difficult to remove at the timing of cesarean hysterectomy. After cesarean hysterectomy, the patient had a vaginal abscess and required antibiotic therapy for approximately two weeks. In the light of our case, authors discuss the timing of removal of cerclage in the cases of PAS.
\end{abstract}

Keywords: Cerclage, Placenta accreta spectrum, Placenta previa, Remove

\section{INTRODUCTION}

Placenta previa is an obstetric complication wherein the placenta is inserted in the lower uterine segment. ${ }^{1}$ In placenta accreta spectrum (PAS), the placenta abnormally penetrates through the myometrium; this is a serious complication of placenta previa and is associated with severe obstetrical hemorrhaging. ${ }^{2,3}$ A well-known risk factor for PAS is a history of one or more previous cesarean deliveries. ${ }^{4,5}$ Management of PAS often requires a cesarean hysterectomy, but the high risk of significant blood loss makes this surgery very difficult.

Cerclage is usually performed to reduce preterm birth rate in the case with cervical insufficiency, short cervix with previous preterm birth and it is usually not difficult to remove. $^{6,7}$ However, the timing of removal is not well known in the cases of PAS at the timing of cesarean hysterectomy. Here authors present a case in whom it was difficult to remove cerclage at the time of cesarean hysterectomy and discuss the timing of removal of cerclage in such cases.

\section{CASE REPORT}

A 38-year-old female (gravida 3, para 2) was referred to our hospital from a private clinic at 28 weeks of gestation because of placenta previa. Her previous pregnancies involved vaginal delivery at term (first pregnancy) and cesarean delivery due to breech presentation with preterm premature rupture of membranes at 35 weeks of gestation (second pregnancy).

Her previous doctor then performed Shirodkar cerclage due to the previous preterm delivery. Transvaginal ultrasonography revealed that her cervical length was 32 $\mathrm{mm}$ diameter and the complete placenta previa was present, with the placenta embedded within the lower 
uterine segment (Figure 1). Magnetic resonance imaging showed a dark band on T2 imaging and the patient was consequently diagnosed with PAS (Figure 2).

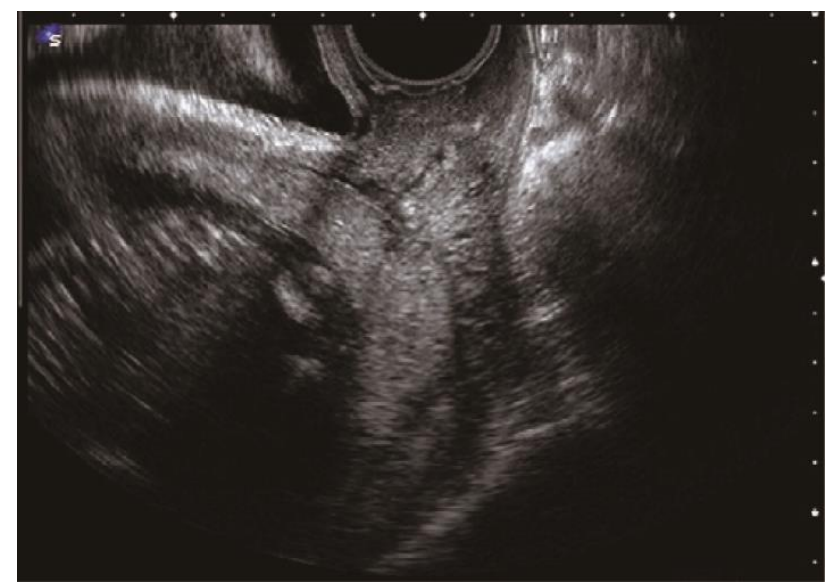

Figure 1: Transvaginal ultrasonography showing the complete placenta previa.

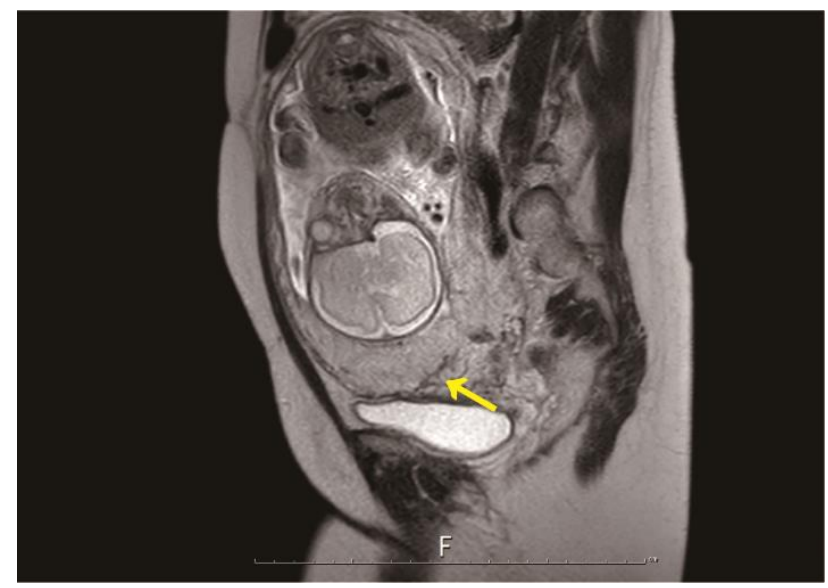

Figure 2: Pelvic magnetic resonance imaging showing a dark band and suspected placenta accreta or increta on T2 imaging; the yellow arrow indicates the irregular thick intraplacental T2 dark bands.

The patient was considered at risk for severe obstetrical complications due to PAS; therefore, a cesarean delivery, followed by hysterectomy, was planned for 34 weeks of gestation, according to the recommendation of the previous studies. ${ }^{8}$ Authors planned to use a transverse fundal incision to avoid iatrogenic incision into the placenta, followed by cesarean hysterectomy, as previously described. ${ }^{9-11}$ Authors decided not to remove cerclage before cesarean delivery, because the removal of cerclage might have caused severe hemorrhaging. Authors planned to resect the uterus with the cerclage, en-bloc. Antenatal corticosteroids for fetal lung maturation were administered at 33 weeks of gestation, because the scheduled delivery was planned for 34 weeks of gestation. On the scheduled day of surgery, cesarean delivery was performed. Laparotomy showed that the placenta was located in the lower uterine segment, and large blood vessels were observed; the placenta could be seen through the lower uterine segment (Figure 3).

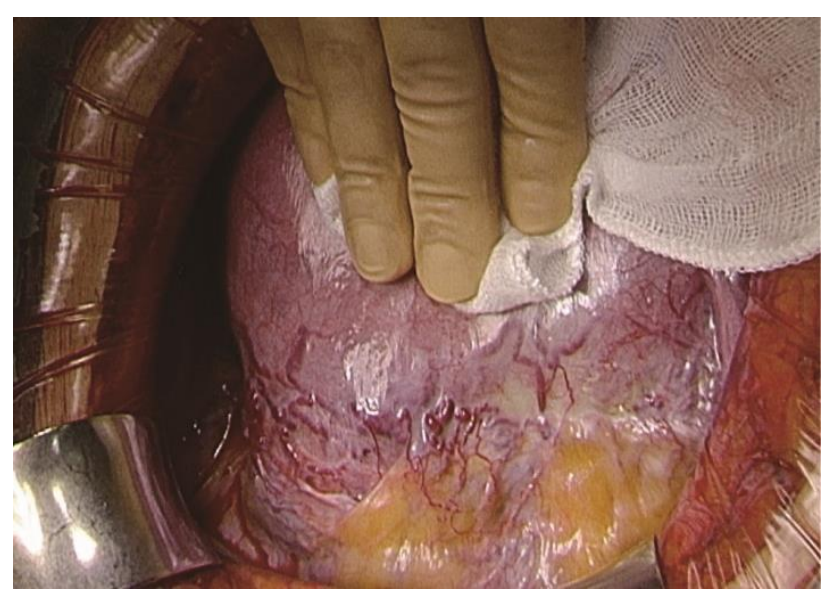

Figure 3: After laparotomy, large blood vessels and part of the placenta could be seen through the anterior uterine wall. From the operative findings, authors suspected placenta accreta spectrum.

From these findings, authors confirmed PAS. After elevating the uterus outside the abdominal wall, an ultrasonographically guided transverse incision was performed, and a healthy female with a birth weight of $1,326 \mathrm{~g}$ was successfully delivered (Apgar scores of 8 and 9 at 1 and $5 \mathrm{~min}$, respectively). Authors then performed a hysterectomy. After resecting the uterus, authors noticed that the cerclage was not resected with the uterus, and careful observation revealed that the cerclage was retained at the vaginal stump. Authors noticed that the cerclage was clamped and sutured to the parametrium. Authors cut the suture in the parametrium and successfully removed the cerclage, and then reclamped and sutured the parametrium. The total estimated blood loss was approximately 1,900 $\mathrm{mL}$ (about $1,300 \mathrm{ml}$ for hysterectomy and about $600 \mathrm{ml}$ for removal of the cerclage); no blood transfusion was required. The post-operative macroscopic and histopathological examination confirmed placenta increta (Figure 4).

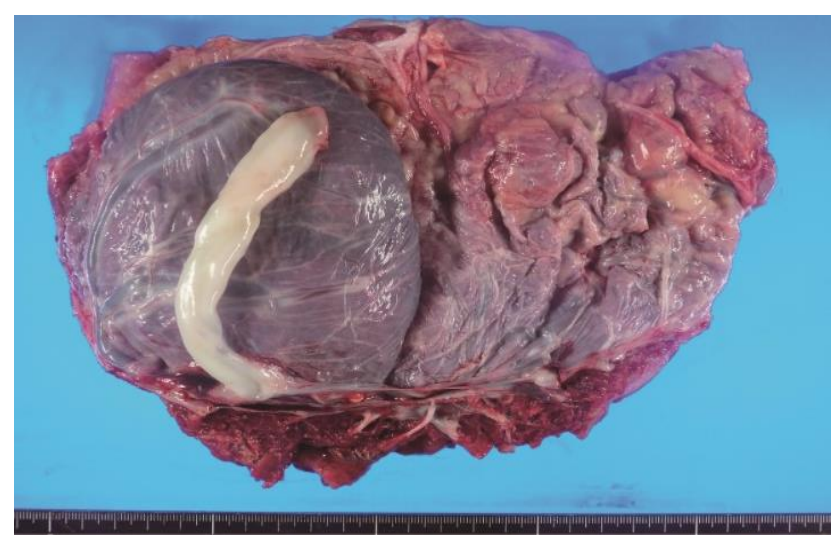

Figure 4: Gross finding of resected uterus showed the placenta accreta spectrum. 
The patient had a fever of $38^{\circ} \mathrm{C}$ on postoperative day (POD) 2 and was administered antibiotics (gentamicin $240 \mathrm{mg} /$ day and clindamycin $1800 \mathrm{mg} /$ day) for 5 days. The fever first improved, but the patient again developed a high fever on POD 8. Foul-smelling vaginal discharge was observed, and an approximately $5 \mathrm{~cm}$ diameter vaginal abscess was observed. Antibiotic therapy (intravenous moxifloxacin $400 \mathrm{mg} /$ day and metronidazole $500 \mathrm{mg} 3$ times/day, orally) was administered for 5 days and the patient's condition improved. The patient was discharged on POD 14, and oral antibiotics (metronidazole $500 \mathrm{mg} 3$ times/day) was prescribed for 5 days. The outpatient clinical course was uncomplicated, and no sign of recurrence of the vaginal abscess was observed.

\section{DISCUSSION}

Present case of PAS was successfully managed but was complicated by a post-operative vaginal abscess because it was difficult to remove the cerclage intra-operatively. To the best of our knowledge, the timing of removal of cerclage in the cases with cesarean hysterectomy is not clear.

In present case, the cerclage was performed due to a previous preterm birth. Recent studies have shown that cerclage could reduce preterm birth in cases with cervical insufficiency and a short cervix, with a history of previous preterm birth. ${ }^{12}$ In our case, the patient had one previous preterm birth without a short cervix; thus, she did not necessarily require prophylactic cerclage. ${ }^{13}$ Therefore, it is important to consider the indications for cerclage carefully, as it has the possibility of causing complications, such as in our case.

PAS is one of the most significant complications of pregnancy because of the risk of heavy obstetrical hemorrhage. A recent study reported that the average blood loss during surgery for PAS is about 3,000 mL, which increases the difficulty of the operative technique. ${ }^{8,14}$ Therefore, the timing of removal cerclage is important. There are four options in terms of the timing of cerclage removal:

- Pre-operative removal

- Intra-operative vaginal removal during cesarean hysterectomy

- En bloc resection of the uterus and cerclage

- Suprahysterectomy without cerclage removal

Authors considered that pre-operative removal of the cerclage was dangerous in the case of PAS, because if the patient suffered severe hemorrhage from the uterine cervix, it might have caused massive hemorrhage. Some authors reported that patients with planned cesarean delivery at or beyond 39 weeks of gestation, cerclage removal at the time of cesarean delivery may be performed. ${ }^{13}$ The cerclage can be left in place until subsequent cesarean delivery. ${ }^{13}$ Therefore, authors concluded that pre-operative removal of the cerclage was not necessary.

Present case showed that en bloc resection of the uterus and cerclage is sometimes difficult. Additionally, our case had additional bleeding during removal of the cerclage and this was complicated by a post-operative vaginal abscess. A previous study showed that cesarean hysterectomy has a higher rate of vaginal abscess or vaginal dehiscence than gynecologic hysterectomy. ${ }^{15}$ Therefore, smooth removal of cerclage is essential to reduce the rate of vaginal abscess. Thus, authors do not recommend en bloc resection of the uterus and cerclage. In our opinion, intra-operative vaginal removal during cesarean hysterectomy or suprahysterectomy represents an appropriate time for cerclage removal. Our case is a rare case of PAS requiring removal of Shirodkar cerclage. To the best of our knowledge, discussion of the timing of removal of cerclage has not been reported; thus, present case could provide useful information. However, this is a report of a single case. Further cases should be accumulated to ascertain the appropriate timing for cerclage removal more conclusively.

In summary, authors successfully managed a case of PAS through a planned hysterectomy; however, authors encountered difficulty in removing the cerclage at the time of cesarean hysterectomy and this resulted in a vaginal abscess. If a clinician encounters a similar case, the timing of removal of the cerclage should be carefully considered.

\section{ACKNOWLEDGMENTS}

Authors would like to thank H. Abe and K. Sakiyama for secretarial assistance.

Funding: No funding sources Conflict of interest: None declared

Ethical approval: The study was approved by the Institutional Ethics Committee

\section{REFERENCES}

1. Silver RM. Abnormal Placentation: Placenta Previa, Vasa Previa, and Placenta Accreta. Obstet Gynecol. 2015;126(3):654-68.

2. Yamada T, Hirahata E, Ihara N, Nishimura D, Inoue K, Kato J, Nagata H, Minamishima S, Morisaki H. Cesarean hysterectomy in a hybrid operating room for placenta percreta: a report of three cases. JA Clinic Rep. 2019;5(1):9.

3. Tanaka M, Matsuzaki S, Matsuzaki S, Kakigano A, Kumasawa K, Ueda Y, Endo M, Kimura T. Placenta accreta following hysteroscopic myomectomy. Clinic Case Rep. 2016;4(6):541.

4. Jauniaux E, Bunce C, Grønbeck L, Langhoff-Roos J. Prevalence and main outcomes of placenta accreta spectrum: a systematic review and meta-analysis. Am J Obstet Gynecol. 2019. 
5. Jauniaux E, Ayres-de-Campos D, Diagnosis FPA, Management Expert Consensus P. FIGO consensus guidelines on placenta accreta spectrum disorders: Introduction. Int J Gynaecol Obstet. 2018;140(3):261-4.

6. Ehsanipoor RM, Seligman NS, Saccone G, Szymanski LM, Wissinger C, Werner EF, et al. Physical Examination-Indicated Cerclage: A Systematic Review and Meta-analysis. Obstet Gynecol. 2015;126(1):125-35.

7. Berghella V, Ludmir J, Simonazzi G, Owen J. Transvaginal cervical cerclage: evidence for perioperative management strategies. Am J Obstet Gynecol. 2013;209(3):181-92.

8. Allen L, Jauniaux E, Hobson S, Papillon-Smith J, Belfort MA, Diagnosis FPA, et al. FIGO consensus guidelines on placenta accreta spectrum disorders: Nonconservative surgical management. Int $\mathbf{J}$ Gynaecol Obstet. 2018;140:281-90.

9. Matsuzaki S, Yoshino K, Kajimoto E, Tanaka Y, Mimura K, Kanagawa T, Kimura T. Successful management of placenta percreta by cesarean hysterectomy with transverse uterine fundal incision. Int J Reprod Contracept Obstet Gynecol. 2014;3(2):447-9.

10. Matsuzaki S, Yoshino K, Mimura K, Kanagawa T, Kimura T. Cesarean delivery via a transverse uterine fundal incision for the successful management of a low-lying placenta and aplastic anemia. Clin Exp Obstet Gynecol. 2016;43(6):262-4.
11. Matsuzaki S, Yoshino K, Kumasawa K, Satou N, Mimura K, Kanagawa T, et al. Placenta percreta managed by transverse uterine fundal incision with retrograde cesarean hysterectomy: a novel surgical approach. Clin Case Rep. 2014;2(6):260-4.

12. Berghella V, Ciardulli A, Rust OA, To M, Otsuki K, Althuisius S, et al. Cerclage for sonographic short cervix in singleton gestations without prior spontaneous preterm birth: systematic review and meta-analysis of randomized controlled trials using individual patient-level data. Ultrasound Obstet Gynecol. 2017;50(5):569-77.

13. American College of O, Gynecologists. ACOG Practice Bulletin No.142: Cerclage for the management of cervical insufficiency. Obstet Gynecol. 2014;123(2 Pt 1):372-9.

14. Sentilhes L, Goffinet F, Kayem G. Management of placenta accreta. Acta Obstet Gynecol Scand. 2013;92(10):1125-34.

15. Hoffman MS, Roberts WS, Fiorica JV, Angel JL, Finan MA, Cavanagh D. Elective cesarean hysterectomy for treatment of cervical neoplasia. An update. J Reprod Med. 1993;38(3):186-8.

Cite this article as: Ito F, Matsuzaki S, Endo M, Kimura T. When is the ideal time to remove cerclage in cases requiring cesarean hysterectomy for placenta accreta spectrum? Int J Reprod Contracept Obstet Gynecol 2019;8:1668-71. 